\title{
Tall or Short? Twenty Years after Preeclampsia Exposure In Utero: Comparisons of Final Height, Body Mass Index, Waist-to-Hip Ratio, and Age at Menarche among Women, Exposed and Unexposed to Preeclampsia during Fetal Life
}

\author{
HELENA SALONEN ROS, PAUL LICHTENSTEIN, ANDERS EKBOM, AND SVEN CNATTINGIUS
}

Department of Medical Epidemiology, Karolinska Institute, SE-171 77 Stockholm, Sweden

\begin{abstract}
Women exposed to preeclampsia during their fetal life are reported to have decreased risk of breast cancer $(1,2)$. Other well-known risk factors for breast cancer are early menarche and tall stature $(3,4)$. Both the association between preeclampsia and breast cancer and the association between early menarche or tall stature and breast cancer have been hypothesized to be caused by intrauterine estrogen exposure (5-7). Therefore, one reasonable hypothesis is that preeclampsia exposure could affect well-known risk factors for breast cancer, such as pubertal development or adult anthropometry, which in turn are important for breast cancer development.
\end{abstract}

indicate that approximately $50 \%$ of the variance in final height was explained by parental heights and birth length for gestational age. Young-adult body mass index was weakly associated with maternal body mass index, maternal smoking, and birth weight for gestational age, which together explained $12 \%$ of the variance. Neither of the assessed maternal or fetal characteristics were significantly associated with age at menarche or waist-tohip ratio. These data indicate that neither adult anthropometry nor age at menarche is in the causal pathway between intrauterine preeclampsia exposure and the reduced risk of breast cancer. (Pediatr Res 49: 763-769, 2001)

\section{BMI, body mass index}

Birth characteristics and adult central obesity are also reported to be associated with breast cancer, coronary heart disease, insulin resistance, and hypertension $(8-13)$, but whether intrauterine exposure to preeclampsia influences the adult fat distribution of growth-restricted individuals is presently not known.

To better understand the biologic pathway for how the intrauterine environment might influence adult morbidity, we assessed the effects of preeclampsia exposure and birth characteristics on known risk factors for breast cancer, such as final height, difference from target height, BMI, waist-to-hip ratio, and age at menarche.

\section{METHODS}

Received June 26, 2000; accepted December 21, 2000.

Correspondence and reprint requests: Helena Salonen Ros, Department of Medical Epidemiology, Karolinska Institute, PO Box 281, SE-171 77 Stockholm, Sweden; e-mail: Helena.Ros@mep.ki.se

Supported by the Swedish Cancer Society (grant 3821-B96-01XAB).

We used the Swedish Medical Birth Register to select every female offspring of women with preeclampsia, born during 1973 through 1978 in a defined geographic area of Sweden 
Table 1. Comparison of maternal and fetal characteristics of the preeclampsia-exposed and-unexposed women, born 1973 through 1978 , 
Table 1. Continued

\begin{tabular}{|c|c|c|c|c|}
\hline \multirow[b]{3}{*}{ Maternal fetal characteristics } & \multicolumn{4}{|c|}{ Preeclampsia } \\
\hline & \multicolumn{2}{|c|}{ Exposed $(n=230)$} & \multicolumn{2}{|c|}{ Unexposed $(n=359)$} \\
\hline & $n$ & $\%$ & $n$ & $\%$ \\
\hline$\leq 45$ & 44 & 19.8 & 10 & 2.8 \\
\hline $46-47$ & 35 & 15.8 & 31 & 8.7 \\
\hline $48-49$ & 53 & 23.9 & 80 & 22.4 \\
\hline Missing & 8 & & 2 & \\
\hline \multicolumn{5}{|l|}{ Birth length for gestational age (SD) } \\
\hline$<-2$ & 37 & 16.8 & 12 & 3.4 \\
\hline-2 to -1.1 & 51 & 23.2 & 46 & 1.9 \\
\hline-1 to 0.9 & 105 & 47.7 & 244 & 68.4 \\
\hline $1-1.9$ & 22 & 10.0 & 44 & 12.3 \\
\hline
\end{tabular}

(including Stockholm, Uppsala, Västerås, Falun, Mora, Örebro, and Bollnäs) with about one third of the Swedish population. A cohort unexposed to preeclampsia was created by a random sample of two female offspring per exposed individual, matched by year and hospital of birth. The second unexposed individual was included only if the record of the first selected was not found when unit records later were scrutinized. Only single births were selected.

Measurements of exposures. The Birth Register contains $>99 \%$ of all births in Sweden (14). Of the women we selected from the register, we were able to retrieve information from individual antenatal and obstetrical records for 99\%. All women had attended antenatal care and followed the standardized routines. In antenatal records, information is prospectively collected from the first to the last antenatal visit. At registration to antenatal care, we obtained information about maternal height, weight, parity, number of previous induced and spontaneous abortions, cigarette smoking, prepregnancy diseases, the date of the first day in the last menstruation, and blood pressure. During pregnancy, blood pressure and proteinuria were measured on a regular basis. After $24 \mathrm{wk}$ gestation, there were visits to the midwife scheduled every second week up till $36 \mathrm{wk}$, and every week thereafter.

Diagnoses of hypertensive diseases during pregnancy were classified according to the Swedish version of International Classification of Diseases, 8th revision (ICD-8 codes 637.03, 637.04, 637.09, and 637.99). To verify exposure status, all individual antenatal and obstetrical records were scrutinized by one of us (H.S.R.) using a structured protocol. Information on the delivery, including inpatient care, mode of delivery, maternal and fetal complications, fetal anthropometry, Apgar score, and health status, was also obtained from the individual records. Birth weight and birth length for gestational age were calculated according to Swedish reference standards, based on births from the 1970s, with gestational age calculated from the date of the last menstruation (15). Before validation of the individual records, approvals from every head of the departments were received.
Mild preeclampsia is defined as a diastolic blood pressure from 90 to $109 \mathrm{~mm} \mathrm{Hg}$ combined with proteinuria of 0.3-4.9 $\mathrm{g} / \mathrm{d}$ or $1+$ or $2+$ on a urine dipstick, occurring during pregnancy. Severe preeclampsia is defined as preeclampsia with either a diastolic blood pressure of $\geq 110 \mathrm{~mm} \mathrm{Hg}$ or proteinuria of $\geq 5 \mathrm{~g} / 24 \mathrm{~h}$ or both. The diagnostic criteria correspond to the criteria proposed by the National High Blood Pressure Education Program Working Group (16). We regarded preeclampsia exposure as too short if the symptoms had occurred the day before delivery or later. Therefore, only women whose mothers had symptoms for $\geq 2 \mathrm{~d}$ before birth were included as being exposed to preeclampsia. After validation of the individual records, we identified 287 pregnancies with preeclampsia, and the unexposed group consisted of 486 individuals.

End point variables. Data on the adult anthropometry of the offspring were retrieved from personal telephone interviews, performed by professional female interviewers during the period November 1997 through April 1998. Before the interview, a brochure with an invitation to participate in the study was sent by mail. Information about the study, some of the questions, a measuring-tape, and instructions with a picture of where and how to measure were also enclosed. The young women, 20 to 25 years old by that time, were asked to measure their height, weight, waist circumference at the level of the umbilicus, and hip circumference at its widest location while standing. They were also asked about age at menarche, parity, and parental heights. The interviewers had no information about exposure status of the individuals or the hypotheses of the study.

In the preeclampsia-exposed cohort $(n=286), 34$ women $(12 \%)$ were lost to follow-up owing to unknown address or telephone number or no answer, and $22(8 \%)$ refused to participate, yielding a response rate of $80 \%$. In the unexposed cohort ( $n=451), 51$ women $(11 \%)$ were lost to follow-up owing to unknown address or telephone number or no answer, and $41(9 \%)$ refused to participate, yielding a response rate of $80 \%$. Mean age (23.5 y) and the number of pregnancies were the same in the exposed and unexposed groups. The propor- 
tions of smokers were $20.9 \%$ and $17.8 \%$ in the exposed and unexposed groups, respectively.

Calculation of target height was performed by using the formula target height $=37.85+0.75$ (mid-parental height), as proposed by Luo et al. (17). BMI is defined as weight (in kilograms) divided by height squared $\left(\mathrm{m}^{2}\right)$, and waist-to-hip ratio is waist circumference divided by hip circumference.

Statistical analyses. Mean values for the end point variables final height, difference from target height, BMI, waist-to-hip ratio, and age at menarche were compared between the exposed and the unexposed cohorts. We performed ANOVA by Scheffé to compare means in more than two groups (for example unexposed, mild preeclampsia, and severe preeclampsia), and $p>0.05$ (two-sided) was considered not significant. For prediction of final height, difference from target height, and BMI, we performed multiple linear regression using the SAS statistical package (18).

Permission to perform the study was granted by the Ethical Committee at the Medical Faculty, Uppsala University, Sweden.

\section{RESULTS}

Table 1 shows comparisons of maternal and fetal characteristics between the group of women who were exposed to preeclampsia and the group of unexposed women. The proportions of nulliparous mothers, mothers with high weight, and nonsmokers were larger in the preeclampsia-exposed group compared with the unexposed group. The proportions of women with low gestational age, low birth weight, and short birth length were larger in the exposed group compared with the unexposed group.

In Table 2, fetal and adult mean anthropometries are compared between exposed and unexposed groups. Exposure status is analyzed in two levels: mild and severe preeclampsia. Compared with the unexposed group, mean gestational age was significantly younger and mean birth weight and birth length for gestational age are significantly smaller for those exposed to mild or severe preeclampsia. There were no significant differences in mean final height, difference from target height, age at menarche, BMI, or waist-to-hip ratio between young women exposed or unexposed to preeclampsia during fetal life.

Table 3 presents the effects of maternal characteristics (height, BMI, and smoking) and birth characteristics (gestational age, birth weight, and length for gestational age) on final height, difference from the target height, and BMI. Maternal height, birth weight, and birth length for gestational age were significantly associated with final height and difference from target height. Maternal BMI, maternal smoking, and birth weight for gestational age were significantly associated with adult BMI. Neither of the independent variables in Table 3 influenced age at menarche or waist-to-hip ratio (data not shown).

Multiple linear regression was performed to estimate the effects of maternal and fetal characteristics on the final height, difference from target height, and BMI. In Table 4, only the best model for each outcome variable is presented (i.e. with only significant factors in the model). Final height was predicted by parental heights and birth length for gestational age, which explained $47 \%$ of the variance in height. The variable estimates indicate that the predicted final height increases approximately $0.3 \mathrm{~cm} / \mathrm{cm}$ increase in each parental height increase, and $1.5 \mathrm{~cm}$ per increase in SD in birth length for gestational age. The ability to reach target height (calculated from parental height) was only predicted from birth length for gestational age, which explained $12.6 \%$ of the variance. BMI in young women was partly (12.2\% of the variance) explained by maternal BMI, maternal smoking, and birth weight for gestational age. For each SD increase in birth weight for gestational age, there was an increase in BMI of $0.29 \mathrm{~kg} / \mathrm{m}^{2}$.

\section{DISCUSSION}

In the present population-based cohort study, we evaluated 230 women who were exposed to preeclampsia in utero and 359 randomly selected unexposed women and compared adult anthropometry and age at menarche. Intrauterine exposure to preeclampsia did not significantly influence final height, BMI, waist-to-hip ratio, or age at menarche. These data indicate that adult anthropometric measures and age at menarche are not in

Table 2. Comparison of fetal and adult anthropometry (expressed as mean values) among preeclampsia-exposed and -unexposed women, born 1973 through 1978, in Sweden

\begin{tabular}{|c|c|c|c|c|c|c|}
\hline \multirow[b]{2}{*}{ Characteristic } & \multicolumn{2}{|c|}{$\begin{array}{l}\text { No preeclampsia } \\
\quad(n=359)\end{array}$} & \multicolumn{2}{|c|}{$\begin{array}{l}\text { Mild preeclampsia } \\
\qquad(n=135)\end{array}$} & \multicolumn{2}{|c|}{$\begin{array}{l}\text { Severe preeclampsia } \\
\qquad(n=95)\end{array}$} \\
\hline & mean & $\mathrm{SD}$ & mean & SD & mean & SD \\
\hline \multicolumn{7}{|l|}{ Birth weight } \\
\hline for gestational age (SD) & -0.1 & 1.0 & $-0.8^{*}$ & 1.6 & $-1.3^{*}$ & 1.2 \\
\hline \multicolumn{7}{|l|}{ Birth length } \\
\hline \multicolumn{7}{|l|}{ Difference } \\
\hline final height-target height (cm) & -0.5 & 5.1 & -0.1 & 4.7 & 0.4 & 5.4 \\
\hline Age at menarche (y) & 13.1 & 1.4 & 12.8 & 1.5 & 13.0 & 1.4 \\
\hline BMI & 22.8 & 3.8 & 22.8 & 3.7 & 22.0 & 3.3 \\
\hline Waist-to-hip ratio & 0.79 & 0.08 & 0.80 & 0.08 & 0.80 & 0.07 \\
\hline
\end{tabular}

* Significantly different from unexposed $(p<0.05)$. 
Table 3. Comparison of final height, differences from target height, and BMI according to paternal height and maternal and fetal characteristics

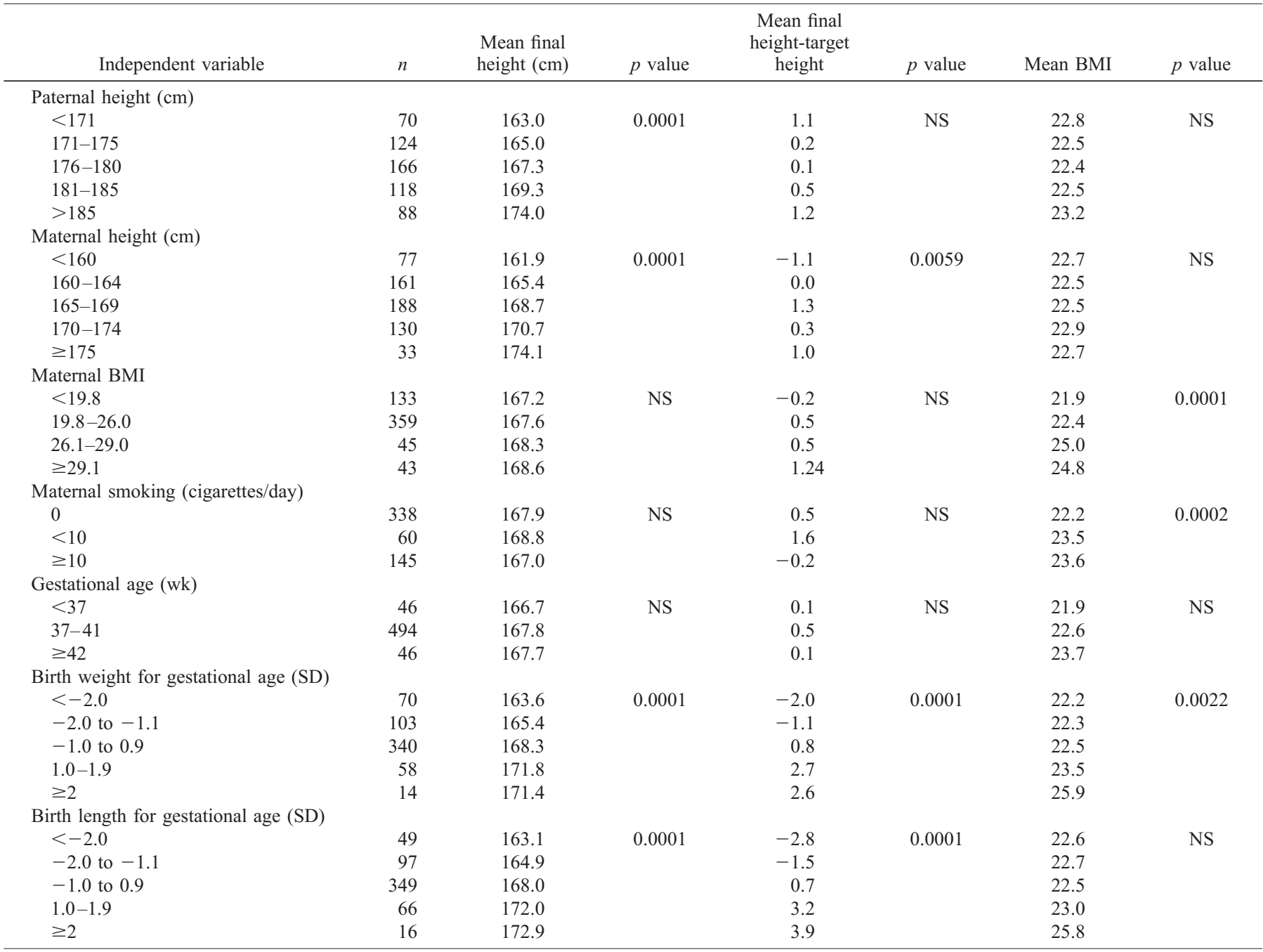

the causal pathway between intrauterine exposure to preeclampsia and decreased risk of breast cancer. Variance in final height was to a large extent explained by parental heights and birth length for gestational age.
Information about exposure status was obtained from prospectively collected data in individual antenatal and obstetrical records, starting at the women's mothers' first visit to antenatal care. Women with verified exposure or nonexposure to pre-

Table 4. Multiple linear regression modeling for prediction of final height, difference from target height, and BMI by maternal and fetal

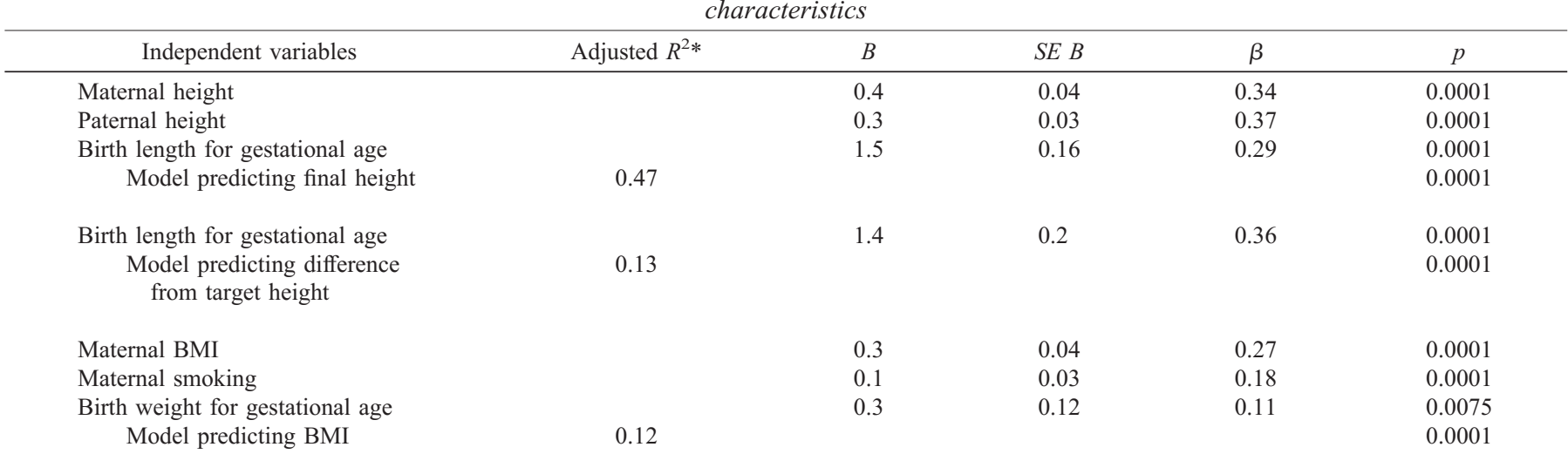

* Adjusted $R^{2}$ denotes the adjusted proportion of the variance explained by the model.

$B$ denotes the variable estimate.

$S E B$ denotes the standard error of the variable estimate.

$\beta$ denotes the standardized estimate. 
eclampsia during fetal life were then interviewed $>20$ y later. The proportion lost to follow-up was only $20 \%$ in both groups. To avoid introduction of recall bias, professional interviewers, who were blinded to exposure status, performed the interviews. Although the study subjects themselves measured some end point variables (weight, height, and waist and hip circumferences), it is highly unlikely that any possible measurement error differs by exposure status.

Altered placental function is described in preeclampsia, and several hormonal factors that may relate preeclampsia to decreased risk of breast cancer have been reported: reduced levels of estrogens (19) and IGF-1 (20), and increased levels of progesterone (21) and androgens $(19,22)$. These factors may influence the offspring through programming, which hypothetically would alter age at menarche or final height. However, there was no effect of preeclampsia on final height or age at menarche, although the mean birth length for gestational age was significantly shorter among daughters of women with preeclampsia. Preeclampsia is probably influenced by genetic factors (23), and one may only speculate whether there may be genetically determined alterations in both the placental and fetal hormonal synthesis, which in turn protects the female fetus against subsequent risk of breast cancer.

The mean birth length for gestational age was significantly shorter among the preeclampsia-exposed women, but they reached the same final height as the unexposed women. Preeclampsia is associated with low birth weight, which in turn is reported to predispose to central obesity (high BMI combined with high waist-to-hip ratio), hypertension, coronary heart disease, and insulin resistance, hypothetically because of fetal programming (24-27). Alternatively, as proposed by Hatterslay and Tooke (28), the association between fetal and adult anthropometry is explained mainly by genetic factors. In the present study, preeclampsia-exposed and -unexposed individuals did not differ in BMI or waist-to-hip ratio in early adulthood. Inasmuch as preeclampsia is associated with hypertension and insulin resistance (29), it is important, as previously suggested $(30,31)$, to include the underlying causes of low birth weight in studies of adult morbidity.

Neither age at menarche nor waist-to-hip ratio were significantly affected by any maternal or infant characteristics. It was recently reported that birth length for gestational age is a better predictor than birth weight for gestational age for the final height in men (32), which is in agreement with our results. We were also able to retrieve data on parental height, and approximately $50 \%$ of the variance in final height could be explained by birth length for gestational age and parental height. For young-adult BMI there were weak associations with maternal BMI, maternal smoking, and birth weight for gestational age, which only explained $12 \%$ of the variance. In contrast to a previous report (33), we found no indication of an association between low birth weight and adult abdominal obesity. This may be because the underlying cause for low birth weight in the present study was preeclampsia.

In conclusion, the results in the present study suggest that exposure to preeclampsia during fetal life does not influence age at menarche or anthropometric measures in young adults.
Thus, prenatal exposure to preeclampsia and adult anthropometry should be regarded as independent risk factors in causative studies of breast cancer.

Acknowledgment. The authors thank Kerstin Stenudd for expert secretarial assistance.

\section{REFERENCES}

1. Innes K, Byers T 1999 Preeclampsia and breast cancer risk. Epidemiology 10:722732

2. Ekbom A, Hsieh CC, Lipworth L, Adami HO, Trichopoulos D 1997 Intrauterine environment and breast cancer risk in women: population-based study. J Natl Cancer Inst 89:71-76

3. Ziegler R, Hoover R, Nomura A, West D, Wu A, Pike M, Lake A, Horn-Ross P, Kolonen L, Siiteri P, Fraumeni J 1996 Relative weight, weight change, height, and breast cancer risk in Asian-American women. J Natl Cancer Inst 88:650-660

4. Lipworth L 1995 Epidemiology of breast cancer. Eur J Cancer Prev 4:7-30

5. Trichopoulos D 1990 Hypothesis: does breast cancer originate in utero? Lancet 335:939-940

6. Kaijser M, Granath F, Jacobsen G, Cnattingius S, Ekbom A 2000 Estriol and fetal anthropometry. Epidemiology 11:315-319

7. Petridou E, Panagiotopoulou K, Katsouyanni K, Spanos E, Trichopoulos D 1990 Tobacco smoking, pregnancy estrogens, and birth weight. Epidemiology 1:247250

8. Michels KB, Trichopoulos D, Robins JM, Rosner BA, Manson JE, Hunter DJ, Colditz GA, Hankinson SE, Speizer FE, Willett WC 1996 Birth weight as a risk factor for breast cancer. Lancet 348:1542-1546

9. Sanderson M, Williams M, Malone K, Stanford J, Emanuel I, White E, Daling J 1996 Perinatal factors and risk of breast cancer. Epidemiology 7:34-37

10. Osmond C, Barker DJP, Winter PD, Fall CHD, Simmonds SJ 1993 Early growth and death from cardiovascular disease. BMJ 307:1519-1524

11. Barker DJP 1995 Fetal origins of coronary heart disease. BMJ 311:171-174

12. Chiarelli F, di Ricco L, Mohn A, De Martino M, Verrotti A 1999 Insulin resistance in short children with intrauterine growth retardation. Acta Paediatr Suppl 88:62-65

13. Forsén T, Eriksson J, Tuomilehto J, Osmond C, Barker D 1999 Growth in utero and during childhood among women who develop coronary heart disease: longitudinal study. BMJ 319:1403-1407

14. Cnattingius S, Eriksson A, Gunnarskog J, Källén B 1990 A quality study of a medical birth registry. Scand J Soc Med 18:143-148

15. Niklasson A, Eriksson A, Fryer J, Karlberg J, Lawrence C, Karlberg P 1991 An update of the Swedish reference standards for weight, length and head circumference at birth for given gestational age (1977-1981). Acta Pædiatr Scand $80: 756-762$

16. National High Blood Pressure Education Program Working Group on high blood pressure in pregnancy. 1990 Am J Obstet Gynecol 163:1689-1712

17. Luo Z, Albertsson-Wikland K, Karlberg J 1998 Target height as predicted by parental heights in a population-based study. Pediatr Res 44:563-571

18. SAS/STAT User's Guide 1989 Version 6, 4th Ed, Vol 1. SAS Institute, Inc., Cary, $\mathrm{NC}$

19. Rosing U, Carlström K 1984 Serum levels of un-conjugated and total oestrogen and dehydroepiandrosterone, progesterone and urinary oestrogen excretion in preeclampsia. Gynecol Obstet Invest 18:199-205

20. Halhali A, Bourges H, Carillo A, Garabedian M 1995 Lower circulating insulin-like growth factor I and 1,25-dihydroxyvitamin D levels in preeclampsia. Rev Invest Clin 47:259-266

21. Walsh S 1988 Progesterone and estradiol production by normal and preeclamptic placentas. Obstet Gynecol 71:222-226

22. Laivuori B, Kaaja R, Rutanen E, Viinikka L, Ylikorkala O 1998 Evidence of high circulating testosterone in women with prior preeclampsia. J Clin Endocrinol Metab 83:344-347

23. Ros H, Lichtenstein P, Lipworth L, Cnattingius S 2000 Genetic effects on the liability of developing pre-eclampsia and gestational hypertension. Am J Med Genet 91:256260

24. Barker M, Robinson S, Osmond C, Barker DJP 1997 Birth weight and body fat distribution in adolescent girls. Arch Dis Child 77:381-383

25. Barker DJP, Hales CN, Fall CHD, Osmond C, Clark PMS 1993 Type 2 (non insulin dependent) diabetes mellitus, hypertension and hyperlipemia (syndrome $\mathrm{X}$ ): relation to reduced fetal growth. Diabetologia 36:62-67

26. Leon D, Lithell H, Vågerö D, Koupilová I, Mohsen R, Berglund L, Lithell UB, McKeigue P 1998 Reduced fetal growth rate and increased risk of death fromischaemic heart disease: cohort study of 15,000 Swedish men and women born 1915-29. BMJ 317:241-245

27. Leger J, Levy-Marchal C, Bloch J, Pinet A, Chevenne D, Porquet D, Collin D, Czernichow P 1997 Reduced final height and indications for insulin resistance in 20 year olds born small for gestational age: regional cohort study. BMJ 315:341-347

28. Hatterslay A, Tooke J 1999 The fetal insulin hypothesis: an alternative explanation of the association of low birthweight with diabetes and vascular disease. Lancet 353:1789-1792

29. Kaaja R, Laivuori H, Laakso M, Tikkanen MJ, Ylikorkala O 1999 Evidence of a state of insuline resistance in preeclampsia. Metabolism 48:892-896 
30. Churchill D, Perry I, Beevers D 1997 Ambulatory blood pressure in pregnancy and fetal growth. Lancet 349:7-10

31. Walker B, McConnachie A, Noon J, Webb D, Watt G 1998 Contribution of parental blood pressures to association between low birth weight and adult high blood pressure: cross sectional study. BMJ 316:834-837
32. Tuvemo T, Cnattingius S, Jonsson B 1999 Prediction of male adult stature using anthropometric data at birth: a nationwide population-based study. Pediatr Res 46:491-495

33. Law M, Barker DJ, Osmond C, Fall CH, Simmonds SJ 1992 Early growth and abdominal fatness in adult life. J Epidemiol Community Health 46:184-186 